\title{
Not taking light lightly
}

\section{2 was an eventful year for optics and photonics, pointing to an exciting yet challenging year ahead.}

Optics and photonic technologies play a key role in driving economic growth by creating jobs and enabling future innovations. Advancements in these fields have consistently changed the way we see, communicate and live.

However, looming budget cuts and tight fiscal conditions have had a dramatic effect on the research funding allocated to science and technology. Research centres worldwide are struggling to sustain a healthy scientific environment, which is hampering the progress of research activities.

The research budget for the National Institute of Nuclear Physics in Italy, whose researchers made key contributions to the discovery of the Higgs boson in July 2012 , is just one example of such cuts. Its budget was shrunk by almost $3.8 \%$ in 2012, corresponding to a loss of about $€ 9$ million, followed by proposed cuts of $10 \%$ in 2013 and 2014, which amounts to further reductions of around $€ 24$ million each year. The Spanish National Research Council - the largest public institution dedicated to research in Spain and the third largest in Europe - has suffered a cumulative budget cut of up to $30 \%$ since 2009 , reaching its lowest point economically in November 2012. The centre needed $€ 147$ million to maintain full functionality in 2013. Although the president of the centre said that $€ 50$ million could be raised from austerity measures such as the total freezing of recruitment from 2013 , they still required $€ 100$ million of financial help from the Spanish Ministry of Economy and Competitiveness. In February 2012, the Japanese government announced salary cuts of $9.77 \%$ for managers and laboratory chiefs and $4.77 \%$ for postdocs and technicians, which caused widespread worry about the country's efforts to maintain an internationally competitive research environment.

In September 2012, the White House Office of Management and Budget released a report on the potential impacts of the automatic budget cuts scheduled for January 2013, in which it detailed how these cuts would affect science-related funding. The budget cuts included US\$62 million for the National Institute of Standards and Technology, US\$400 million for the Department of Energy Office of Science, US\$23 million for the Department of Energy Advanced Research Projects Agency,

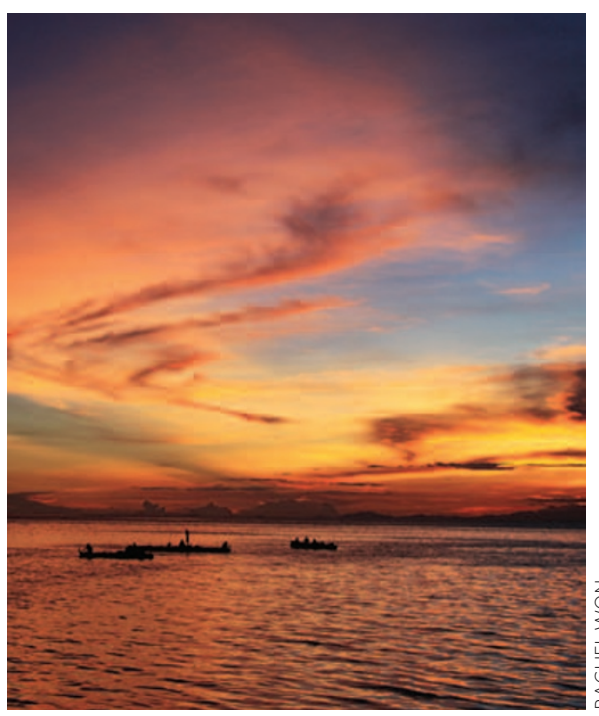

and government, and to steer federal research and development funding and activities.

In October 2012, the European and African Physical Societies, on behalf of a global partnership across more than 40 scientific societies, academies and institutions, in collaboration with the United Nations Educational, Scientific and Cultural Organization (UNESCO) International Basic Sciences Programme, announced that the UNESCO Executive Board had enthusiastically supported the proposal to declare an International Year of Light in 2015. The mission of the International Year of Light is to promote improved public and political understanding of the global importance of light and optical technologies in our lives, for our future and for the development of society. Still waiting for the final declaration by the United Nations (UN), the programme will consist of

US $\$ 2.53$ billion for the National Institutes of Health, US $\$ 417$ million for the National Aeronautics and Space Administration science programmes, US\$586 million for the National Science Foundation and US\$7.47 billion for the Department of Defense Research, Development, Test and Evaluation programmes.

Under such difficult circumstances, it is hardly surprising that research funding for optics and photonics has suffered similar cutbacks. Optics and photonics researchers, together with the wider scientific community, are watching closely and reacting cautiously to the situation.

In September 2012, in order to raise awareness about the importance of optics and photonics to key stakeholders in US federal agencies such as the National Institute of Standards and Technology, the National Science Foundation and the Department of Energy, members of the optics and photonics community headed to Capitol Hill in Washington D.C., where they drew attention to the National Academy of Sciences' recently released report entitled "Optics and Photonics: Essential Technologies for Our Nation". The report details the current state of optical sciences and the role they could play in driving US economic growth in the future. It identifies research priorities and grand challenges to fill gaps in optics and photonics, and it recommends that the federal government develops an initiative to foster collaboration between academia, industry coordinated activities in science, education and development, focusing particularly on how light can improve the quality of life in the developing world and in emerging economies.

The significance of optics and photonics has also been endorsed by a number of recent celebratory events. Charles Townes, 1964 Nobel Laureate for his part in the pioneering research that led to the development of the laser, was awarded the first Golden Goose - a new award that recognizes scientists and engineers whose federally funded research has provided significant human and economic benefits. In addition, last year's Nobel Prize for physics was awarded to two scientists, Serge Haroche and David Wineland, who worked out a way to trap, manipulate and study the fundamental particles of light and matter without destroying them. They won the prize "for groundbreaking experimental methods that enable measuring and manipulation of individual quantum systems." Their work is a crucial step towards building superfast quantum computers and could lead to ways of measuring time at precisions hundreds of times better than those of atomic clocks.

It is certainly motivating for researchers in the optics and photonics community to see all these efforts and endorsements dedicated to the field. Amidst budget cuts, let's hope the essential roles of optics and photonics are well-understood by the public and that the field continues to shine, building a brighter future for everyone. 